\title{
Anaemia and iron deficiency between 2003 and 2007 in Amazonian children under 2 years of age: trends and associated factors
}

\author{
Fernanda Serra Granado ${ }^{1}$, Rosangela Aparecida Augusto ${ }^{1}$, Pascoal Torres Muniz ${ }^{2}$ and \\ Marly Augusto Cardoso ${ }^{1, *}$, the ACTION Study Team \\ 'Department of Nutrition, School of Public Health, University of São Paulo, Av. Dr Arnaldo 715, São Paulo, \\ SP 01246-904, Brazil: ${ }^{2}$ Department of Health Sciences, Federal University of Acre, Rio Branco, Brazil
}

Submitted 29 June 2012: Final revision received 6 November 2012: Accepted 6 December 2012: First published online 1 February 2013

\begin{abstract}
Objective: To describe trends in the prevalence of anaemia and Fe deficiency in children under 2 years of age living in a town in western Brazilian Amazonia. Design: Temporal analysis of two cross-sectional population-based surveys. Information on socio-economic status, morbidity and breast-feeding was obtained using a structured questionnaire. Child weight and length were measured for anthropometric evaluation. Concentrations of blood $\mathrm{Hb}$, plasma ferritin and soluble transferrin receptor were measured.

Setting: The town of Acrelândia, state of Acre, north-west Brazil.

Subjects: A total of 170 and 224 participants of the 2003 and 2007 surveys, respectively.

Results: Comparison between the 2003 and 2007 surveys revealed no statistically significant differences in the prevalence of anaemia ( 48 (95\% CI 39, 56) \% to $40(95 \%$ CI 33, 47) \%) or Fe-deficiency anaemia (39 (95\% CI 30, 48) \% to 37 (95\% CI 30, 45) \%), respectively. However, an increase in the overall prevalence of Fe deficiency from 62 (95\% CI 51, 68) \% to 81 (95\% CI 75, 86) \% was observed $\left(\chi^{2}\right.$ test, $\left.P \leq 0 \cdot 001\right)$. In age- and sex-adjusted analyses for risk of Fe deficiency, only early introduction of cow's milk $(<90 \mathrm{~d})$ was associated with Fe deficiency in 2003 (prevalence ratio $(\mathrm{PR})=0 \cdot 76 ; 95 \% \mathrm{CI} 0 \cdot 57,1 \cdot 01$ ), while caesarean section $(\mathrm{PR}=1 \cdot 18$; $95 \% \mathrm{CI} 1 \cdot 03,1 \cdot 35)$ and birth weight $<3500 \mathrm{~g}(\mathrm{PR}=1 \cdot 15 ; 95 \% \mathrm{CI} 1 \cdot 00$, 1.34) were associated with Fe deficiency in 2007.

Conclusions: No improvements were observed in the prevalence of anaemia, exposing a worrying scenario for public health, while a significant increase was found in the prevalence of Fe deficiency in the studied infants and toddlers.
\end{abstract}

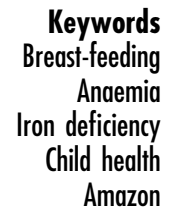

Iron deficiency (ID) is the most common and widespread nutritional deficiency in the world. ID affects both industrialized and developing nations and has been identified as the main determinant in cases of anaemia among infants under 2 years of age ${ }^{(1)}$. According to the WHO, nutritional anaemia is considered a public health problem in $76 \%$ of all countries, predominantly affecting children. Estimates show that between $66 \%$ and $80 \%$ of the world's population is Fe deficient while $30 \%$ is anaemic, corresponding to about two billion individuals ${ }^{(2)}$.

In Brazil, according to figures from the 2006 National Demographic and Health Survey (PNDS) ${ }^{(3)}$, about $50 \%$ of children under the age of 5 years are anaemic, a prevalence which rises further in infants under 2 years of age or from low-income families. This situation is highly worrying since ID and anaemia are linked to greater infant mortality and morbidity, stunting, retardation of motor and cognitive development, as well as reduced intellectual capacity, and often have irreversible effects ${ }^{(1)}$.

Children under 2 years old, particularly those residing in poorer regions, are at greater risk of ID since the higher requirement for the mineral for growth in this group is often not met due to low body reserves of Fe at birth, inadequate intake characterized by low quantity and bioavailability of $\mathrm{Fe}$ in complementary foods, and as a result of more frequent infections ${ }^{(1,4,5)}$.

In order to ensure better nutrition in the first years of life and prevent nutritional deficiencies, the $\mathrm{WHO}^{(6)}$ recommends that infants be exclusively breast-fed until 6 months old and continue to receive breast milk, together with nutritionally safe and suitable complementary food, up to 2 years of age or older. Despite these recommendations, the practice of early weaning and inadequate complementation of breast-feeding is common in many parts of the world. 
Brazilian strategies for the prevention of ID include government adoption of the National Program for Iron Supplementation $(\mathrm{PNSF})^{(7)}$ aimed at infants aged 6-18 months, pregnant or puerperal women; and since 2004, a programme of compulsory fortification of wheat and corn flours with $4.2 \mathrm{mg}$ of Fe and $150 \mu \mathrm{g}$ of folic acid per $100 \mathrm{~g}^{(8)}$. In addition to the combined interventions of Fe supplementation and compulsory flour fortification for the prevention of $\operatorname{ID}^{(7,8)}$, in recent years Brazil has seen a major expansion in the Family Health Program (FHP), created to reach individuals from the most impoverished regions of the country ${ }^{(9)}$. However, few studies assessing the effectiveness of these actions for reducing ID in young infants are available, particularly in the Amazon region. The $\mathrm{WHO}^{(4)}$ recommends regular population-based surveys to examine the prevalence and associated factors for anaemia and ID, in order to help guide future government actions. In spite of these recommendations, many developing countries have no data available assessing the magnitude of ID in childhood or its evolution in recent years in the presence of prevailing public health programmes and policies ${ }^{(1)}$.

The present study reports a temporal series of two cross-sectional population-based surveys conducted in 2003 and 2007 in a town in western Brazilian Amazonia, to assess trends in the prevalences of anaemia and ID in children under 2 years old. Studies of this nature are scarce in Brazil and also in other developing countries ${ }^{(4)}$. No national estimates of ID in the general population or among at-risk subgroups are available.

\section{Materials and methods}

\section{Study design and population}

A temporal analysis was performed involving two population-based studies conducted in January 2003 and December 2007, respectively, in Acrelândia, a town situated $100 \mathrm{~km}$ from Rio Branco, the capital of Acre State. In January 2003, we conducted a population-based crosssectional study in Acrelândia with the assistance of local teams of the FHP of the Brazilian Ministry of Health ${ }^{(10)}$. All households from this urban area with children aged $<5$ years were identified and invited to participate ( $n$ 334), and only two declined participation. Data were collected from 332 households (99.4\%) involving a total of 477 children. In December 2007, using registers from the FHP in the town, a total of 749 households with 1225 children aged $<10$ years were identified. Of this total, 1151 children took part in the study $(94 \cdot 0 \%$ of those eligible), as reported elsewhere ${ }^{(11)}$. The present analyses included all children under the age of 2 years assessed in the 2003 survey ( $n$ 170) and the 2007 survey ( $n$ 224). Sampling strategies and additional information on the two surveys can be found in earlier publications ${ }^{(12,13)}$.

The field research team comprised researchers involved in the study from the University of São Paulo and the Federal University of Acre (including physicians and nutritionists), community health workers and health professionals from the FHP. Socio-economic, demographic and health data were collected using a structured questionnaire. Anthropometric measurements, dietary intake data and maternal breast-feeding practices were obtained through the application of clinical, biochemical and parasitological examinations. Diarrhoea (defined as three or more liquid evacuations within a $24 \mathrm{~h}$ period) during the $15 \mathrm{~d}$ leading up to the survey was recorded. Community health workers were trained by the study researchers to carry out household interviews by introducing themselves, explaining the objectives of the survey, and requesting voluntary participation and signing of the Free and Informed Consent Form by children's parents or guardians. The study was approved by the Research Ethics Committee of the Public Health Faculty of the University of São Paulo (under research protocol no. 2166).

\section{Measures}

\section{Anthropometric measurements}

Length and weight were measured by trained research assistants employing standardized procedures on calibrated equipment ${ }^{(14)}$. Length was measured with children in the dorsal decubitus position using a portable wooden infantometer, accurate to the nearest $0 \cdot 1 \mathrm{~cm}$, on a flat surface. Children were placed barefoot in a central standing position in the stadiometer, with head, shoulders, buttocks and heels pressed against the wall. Weight measurements were taken on an electronic scale (model HS-302; Tanita, Tokyo, Japan) and recorded to the nearest $100 \mathrm{~g}$. Each measurement was repeated and the mean value calculated. Birth date was recorded directly from birth certificates or child health cards. Length-for-age $Z$-scores were calculated where the cut-off for stunting $(<-2)$ was defined according to WHO child growth standards ${ }^{(15)}$.

\section{Laboratory measurements}

Fasting venous blood samples were collected by trained nursing assistants. At the field laboratory in Acrelândia, $\mathrm{Hb}$ concentrations were measured on a portable haemoglobin photometer (HemoCue AB, Angelholm, Sweden), recommended by the WHO for use in epidemiological studies $^{(16)}$. A separate blood sample was centrifuged within $1 \mathrm{~h}$ of collection; plasma samples were shipped to São Paulo on dry ice and frozen at $-70^{\circ} \mathrm{C}$ until further analysis. In São Paulo, plasma ferritin (PF) and soluble transferrin receptor (sTfR) concentrations were measured using commercially available enzyme immunoassays (Ramco, Houston, TX, USA). Anaemia, ID and iron-deficiency anaemia (IDA) were defined according to $\mathrm{Hb}, \mathrm{PF}$ and sTfR concentrations as follows ${ }^{(17,18)}$ : anaemia was defined as $\mathrm{Hb}$ concentration $<110 \cdot 0 \mathrm{~g} / \mathrm{l}$ (for children $>6$ months of age); ID was defined when PF concentration was low $(<12 \mu \mathrm{g} / \mathrm{l})$ or sTfR 
concentration was high $(>8 \cdot 3 \mathrm{mg} / \mathrm{l})$; IDA was defined when ID occurred in anaemic children.

Stool samples were collected in plastic containers containing a preservative solution $(10 \% \mathrm{w} / \mathrm{v}$ formalin). Since variable volumes of faeces were mixed with formalin for preservation, no attempt was made to perform egg counts. The stool samples were examined for parasite ova, cysts and larvae as described elsewhere ${ }^{(19)}$.

Children with anaemia or intestinal parasites detected during the surveys received free treatment prescribed by research clinicians.

\section{Breast-feeding indicators}

Based on current information on breast-feeding and the introduction of water, tea infusions or foods, the children were considered to be exclusively breast-fed when consuming only breast milk without other foods, water and/ or tea infusions, but in use of drops and/or syrups. This information was used to determine the age at introduction of cow's milk, considered early introduction when given to infants before the age of $90 \mathrm{~d}$ based on the median age for weaning observed in our study population.

\section{Statistical analysis}

Nutritional deficiencies, socio-economic situation and health status of the children were expressed in terms of proportion of the sample and the respective 95\% confidence interval, while means and standard deviations were also provided for some characteristics. For both surveys, it was checked whether the prevalence of ID differed according to the characteristics of the children studied. The ID prevalence in 2003 and 2007 was also compared according to children's characteristics. Comparisons were made using Pearson's $\chi^{2}$ test for categorical variables and Student's $t$ test for continuous variables. Then, crude analyses were first conducted using Poisson regression models between the dependent variable of interest (ID) and the explanatory variables. Adjusted prevalence ratios (PR) and 95\% confidence intervals were obtained for the factors associated with ID using multiple Poisson regression models with robust variance. At each level of determination, covariates were retained in the model if they were associated with the outcome or if their inclusion in the model changed the PR by $10 \%$ or more. Missing observations were included in the multiple models by creating missing-value categories. All analyses were performed using the Stata statistical software package version $11 \cdot 0$. The level of significance adopted was $P \leq 0.05$ for all analyses.

\section{Results}

Table 1 depicts the general characteristics of the children studied based on the data from the two surveys. Children were evenly distributed by gender and age in both surveys.

Table 1 General characteristics of children under 2 years of age and maternal health-care assistance according to the 2003 and 2007 surveys in Acrelândia, Acre State, north-west Brazil

\begin{tabular}{|c|c|c|c|c|}
\hline \multirow[b]{2}{*}{ Variable } & \multicolumn{2}{|c|}{$2003(n 170)$} & \multicolumn{2}{|c|}{2007 (n 224) } \\
\hline & $\%$ & $n /$ totalt & $\%$ & $n /$ totalt \\
\hline \multicolumn{5}{|l|}{ Gender } \\
\hline Male & $48 \cdot 8$ & $83 / 170$ & $49 \cdot 1$ & $110 / 224$ \\
\hline Female & $51 \cdot 2$ & $87 / 170$ & $50 \cdot 9$ & $114 / 224$ \\
\hline \multicolumn{5}{|l|}{ Age group (months) } \\
\hline $0-6$ & $18 \cdot 2$ & $31 / 170$ & $13 \cdot 8$ & $31 / 224$ \\
\hline $6-12$ & $30 \cdot 6$ & $52 / 170$ & $25 \cdot 9$ & $58 / 224$ \\
\hline $12-18$ & $27 \cdot 1$ & $46 / 170$ & $30 \cdot 0$ & $67 / 224$ \\
\hline $18-25$ & $24 \cdot 1$ & $41 / 170$ & $30 \cdot 4$ & $68 / 224$ \\
\hline \multicolumn{5}{|l|}{ First prenatal visit* } \\
\hline First trimester & $28 \cdot 3$ & $39 / 138$ & $53 \cdot 5$ & $106 / 198$ \\
\hline Second trimester & $63 \cdot 0$ & $87 / 138$ & $40 \cdot 4$ & $80 / 198$ \\
\hline Third trimester & $8 \cdot 7$ & $12 / 138$ & $6 \cdot 1$ & $12 / 198$ \\
\hline \multicolumn{5}{|l|}{ Prenatal visits* } \\
\hline$<6$ visits & $32 \cdot 9$ & $45 / 137$ & $19 \cdot 3$ & $39 / 202$ \\
\hline$\geq 6$ visits & $67 \cdot 2$ & $92 / 137$ & $80 \cdot 7$ & $163 / 202$ \\
\hline \multicolumn{5}{|l|}{ Type of delivery** } \\
\hline Vaginal & $75 \cdot 0$ & $114 / 152$ & $62 \cdot 1$ & $128 / 206$ \\
\hline Caesarean section & $25 \cdot 0$ & $38 / 152$ & $37 \cdot 9$ & $78 / 206$ \\
\hline Low birth weight $(<2500 \mathrm{~g})$ & $8 \cdot 4$ & $14 / 166$ & $6 \cdot 7$ & $14 / 210$ \\
\hline Immunization coverage* & $85 \cdot 3$ & $145 / 170$ & $92 \cdot 9$ & $208 / 224$ \\
\hline Presence of parasite in stool sample & $18 \cdot 0$ & $25 / 139$ & $22 \cdot 8$ & $44 / 193$ \\
\hline Diarrhoea in the $15 \mathrm{~d}$ before survey & $37 \cdot 9$ & $64 / 169$ & $43 \cdot 7$ & 97/222 \\
\hline Treated water supply coverage & $50 \cdot 0$ & $83 / 167$ & $58 \cdot 6$ & $130 / 222$ \\
\hline \multicolumn{5}{|l|}{ Father's schooling* } \\
\hline$<5$ years & $51 \cdot 0$ & $76 / 149$ & $34 \cdot 3$ & $62 / 181$ \\
\hline$\geq 5$ years & $49 \cdot 0$ & $73 / 149$ & $65 \cdot 8$ & $119 / 181$ \\
\hline
\end{tabular}

${ }^{\star} P \leq 0.05,{ }^{*} P \leq 0.01$ for difference between 2003 and 2007.

†Totals differ from the total number of study children due to missing values. 
Table 2 Nutritional characteristics and breast-feeding practices of children under 2 years of age according to the 2003 and 2007 surveys in Acrelândia, Acre State, north-west Brazil

\begin{tabular}{|c|c|c|c|c|c|c|}
\hline \multirow[b]{2}{*}{ Variable } & \multicolumn{3}{|c|}{$2003(n$ 170) } & \multicolumn{3}{|c|}{$2007(n$ 224) } \\
\hline & $\%$ & n/totalt & $95 \% \mathrm{Cl}$ & $\%$ & n/totalt & $95 \% \mathrm{Cl}$ \\
\hline$I D^{*}$ & $61 \cdot 8$ & $84 / 136$ & $51 \cdot 4,68 \cdot 2$ & $80 \cdot 7$ & $167 / 207$ & $74 \cdot 6,85 \cdot 8$ \\
\hline Anaemiał & $47 \cdot 5$ & $66 / 139$ & $39 \cdot 0,56 \cdot 1$ & $39 \cdot 7$ & $75 / 189$ & $32 \cdot 7,47 \cdot 0$ \\
\hline IDA & 38.9 & $49 / 126$ & $30 \cdot 3,48 \cdot 0$ & $37 \cdot 2$ & $68 / 183$ & $30 \cdot 1,44 \cdot 6$ \\
\hline Exclusive breast-feeding in children $<6$ months old & $22 \cdot 6$ & $7 / 31$ & $9 \cdot 6,41 \cdot 1$ & $16 \cdot 1$ & $5 / 31$ & $5 \cdot 5,33 \cdot 7$ \\
\hline Early introduction of cow's milk ( $<90 \mathrm{~d})$ & $37 \cdot 6$ & $62 / 165$ & $30 \cdot 2,45 \cdot 4$ & $29 \cdot 0$ & $65 / 224$ & $23 \cdot 2,35 \cdot 4$ \\
\hline Stunting & 8.9 & $15 / 169$ & $5 \cdot 1,14 \cdot 2$ & $11 \cdot 4$ & $25 / 219$ & $7 \cdot 5,16 \cdot 4$ \\
\hline
\end{tabular}

ID, iron deficiency; IDA, iron-deficiency anaemia.

${ }^{\star} P \leq 0.001$ for difference between 2003 and 2007.

†Totals differ from the total number of study children due to missing values.

$\ddagger$ Only for children $\geq 6$ months old.

Children's mean age was $12 \cdot 0$ (SD 6.5) months in the 2003 survey and $13 \cdot 8$ (SD 6.4) months in the 2007 survey. Regarding general characteristics of the children studied, between 2003 and 2007, no statistically significant improvements were found in rates of low birth weight, use of vitamin and/or mineral supplements, infection by intestinal parasites, or occurrence of diarrhoea. No increase in coverage of treated water supply was evident while the absence of sewage treatment and collection in the region remained. Statistically significant improvements in prenatal care were noted, where attendance during the first trimester of pregnancy virtually doubled from $28.3 \%$ to $53.5 \%$. Similarly, a greater percentage of mothers attended a higher number of consultations ( $\geq 6$ visits). However, in contrast, there was a statistically significant increase (about 50\%) in the number of caesarean sections in 2007. Some positive findings were an increase in immunization coverage, reaching almost $100 \%$ of children surveyed in 2007, and longer paternal schooling period with an average increase from 5 to 7 years of schooling.

With regard to nutritional indicators, between 2003 and 2007 , no reduction in the prevalence of anaemia, stunting or breast-feeding indicators was evident, where this latter parameter was marked by low prevalence of exclusive breast-feeding and high frequency of early introduction of cow's milk. In addition to the absence of nutritional improvements, a significant increase in the prevalence of ID was observed, which rose by $30 \%$ and affected $80.7 \%$ of children in 2007 (Table 2).

In a stratified analysis of the prevalence of ID by child characteristics, ID prevalence in 2007 was significantly higher among children under 12 months of age, among boys, in infants delivered by caesarean section and in those with a birth weight of $<3500 \mathrm{~g}$ (Table 3). The analysis of ID increase by child characteristics between 2003 and 2007 showed a significant overall rise of about $30 \%$, a $65 \%$ increase in children aged younger than 12 months and a $38 \%$ increase in neonates with a birth weight of $<3500 \mathrm{~g}$. A higher prevalence of ID was also detected according to type of delivery (a 23\% increase for normal deliveries $v$. $27 \%$ for caesarean deliveries).
In 2003, only early introduction of cow's milk was retained in age- and sex-adjusted multiple regression models for ID risk. In 2007 though, after adjusting for sex and age groups, caesarean section and birth weight <3500g remained positively associated with ID (Table 3 ).

\section{Discussion}

Acrelândia is a frontier town situated $112 \mathrm{~km}$ east of Rio Branco, the capital of Acre State, in western Brazilian Amazonia. The urban inhabitants are mainly migrants from south-east and south Brazil who are engaged in commercial agriculture and raising cattle. Infant mortality in Acrelândia, estimated at 70.7/1000 live births in 2000 , is substantially higher than the country average $(27 \cdot 7 / 1000$ live births $)^{(20)}$. The scenario exposed in the present study is of great concern, revealing no improvements in terms of basic sanitation over the period spanned by the two studies. Additionally, persistence in stunting among under- $2 \mathrm{~s}$ of about $11 \%$ was noted, four times the level expected in a well-nourished population ${ }^{(21)}$, along with a high rate of anaemia of about $40 \%$ representing a major public health problem ${ }^{(4)}$. Importantly, results after 4 years showed a significant increase of about $30 \%$ in the prevalence of ID in 2007 compared with 2003 levels, with ID affecting $80 \%$ of children under 2 years of age. Despite the great advances in the Brazilian economy over recent years, now ranked among the top ten globally, the high prevalences of anaemia and ID found in Acrelândia are akin to those seen in more impoverished regions such as Africa and South-East Asia ${ }^{(4)}$. This situation points to an urgent need for more effective health and nutrition actions, particularly in poorer regions such as the Amazon.

The nutritional status of children under 2 years of age in the Brazilian Amazon, as well as in many other poorer regions in the world, has been largely attributed to a set of interrelated factors. Primarily, factors implicated include the mother-child binomial, with intergenerational transfer of low Fe reserves associated with gestational and delivery characteristics (low quality of prenatal care, poor adherence to use of mineral and vitamin supplements 
Table 3 Prevalence of ID and PR for risk of ID according to characteristics of children under 2 years of age in the 2003 and 2007 surveys in Acrelândia, Acra State, north-west Brazil

\begin{tabular}{|c|c|c|c|c|c|c|c|c|c|c|c|c|}
\hline \multirow[b]{3}{*}{ Variable } & \multicolumn{6}{|c|}{2003} & \multicolumn{6}{|c|}{2007} \\
\hline & \multicolumn{2}{|c|}{ ID } & \multicolumn{2}{|c|}{ Crude } & \multicolumn{2}{|c|}{ Adjusted } & \multicolumn{2}{|c|}{ ID } & \multicolumn{2}{|c|}{ Crude } & \multicolumn{2}{|c|}{ Adjusted } \\
\hline & $\%$ & n/totalt & PR & $95 \% \mathrm{Cl}$ & PR & $95 \% \mathrm{Cl}$ & $\%$ & $n /$ totalt & PR & $95 \% \mathrm{Cl}$ & PR & $95 \% \mathrm{Cl}$ \\
\hline \multicolumn{13}{|l|}{ Sex } \\
\hline Female & $56 \cdot 9$ & $41 / 72$ & $1 \cdot 00$ & Ref. & $1 \cdot 00$ & Ref. & $74 \cdot 5^{\star}$ & $76 / 102$ & $1 \cdot 00$ & Ref. & 1.00 & Ref. \\
\hline Male & $67 \cdot 2$ & $43 / 64$ & $1 \cdot 18$ & $0.91,1.54$ & $1 \cdot 15$ & $0.90,1.50$ & $86 \cdot 7^{\star}$ & $91 / 105$ & $1 \cdot 16$ & $1 \cdot 01,1 \cdot 33$ & $1 \cdot 18$ & $1 \cdot 02,1 \cdot 34$ \\
\hline \multicolumn{13}{|l|}{ Age group (months) } \\
\hline$<12$ & $45 \cdot 5$ & $25 / 55$ & $1 \cdot 00$ & Ref. & $1 \cdot 00$ & Ref. & $75 \cdot 0^{\star}$ & $57 / 76$ & $1 \cdot 00$ & Ref. & 1.00 & Ref. \\
\hline $12-25$ & $72 \cdot 8$ & $59 / 84$ & $1 \cdot 60$ & $1 \cdot 16,2 \cdot 21$ & 1.59 & $1 \cdot 15,2 \cdot 19$ & $84 \cdot 0$ & $110 / 167$ & $1 \cdot 12$ & $0.96,1.30$ & $1 \cdot 14$ & $0.98,1.31$ \\
\hline \multicolumn{13}{|l|}{ Wealth index } \\
\hline 1st tertile (lower) & $69 \cdot 6$ & $32 / 46$ & $1 \cdot 00$ & Ref. & - & - & $81 \cdot 8$ & $54 / 66$ & 1.00 & Ref. & - & - \\
\hline 2nd tertile & $60 \cdot 0$ & $24 / 40$ & 0.86 & $0.67,1.19$ & - & - & $81 \cdot 8$ & $54 / 66$ & $1 \cdot 00$ & $0 \cdot 85,1 \cdot 17$ & - & - \\
\hline 3rd tertile (higher) & $55 \cdot 3$ & $26 / 47$ & 0.80 & $0.58,1 \cdot 10$ & - & - & $78 \cdot 7$ & $59 / 75$ & 0.96 & $0 \cdot 82,1 \cdot 13$ & - & - \\
\hline \multicolumn{13}{|l|}{ Father's schooling } \\
\hline$<5$ years & $60 \cdot 7$ & $34 / 56$ & 1.00 & Ref. & - & - & $89 \cdot 9$ & $45 / 53$ & $1 \cdot 00$ & Ref. & - & - \\
\hline$\geq 5$ years & $61 \cdot 7$ & $37 / 60$ & $1 \cdot 02$ & $0 \cdot 80,1 \cdot 36$ & - & - & $78 \cdot 9$ & $90 / 114$ & 0.93 & $0.80,1.08$ & _- & - \\
\hline \multicolumn{13}{|l|}{ Type of delivery } \\
\hline Vaginal & $60 \cdot 0$ & $54 / 90$ & 1.00 & Ref. & - & - & $73 \cdot 7^{\star}$ & $87 / 118$ & $1 \cdot 00$ & Ref. & $1 \cdot 00$ & Ref. \\
\hline Caesarean section & $70 \cdot 0$ & $21 / 30$ & $1 \cdot 17$ & $0.87,1.56$ & - & - & $88 \cdot 9^{*}$ & $64 / 72$ & $1 \cdot 21$ & $1 \cdot 05,1 \cdot 38$ & $1 \cdot 18$ & $1 \cdot 03,1 \cdot 35$ \\
\hline \multicolumn{13}{|c|}{ Early introduction of cow's milk (<90 d) } \\
\hline No & $68 \cdot 2$ & $58 / 85$ & $1 \cdot 00$ & Ref. & $1 \cdot 00$ & Ref. & $83 \cdot 0$ & $122 / 147$ & $1 \cdot 00$ & Ref. & - & - \\
\hline Yes & $54 \cdot 4$ & $25 / 46$ & $0 \cdot 80$ & $0.59,1.08$ & $0 \cdot 76$ & $0.57,1.01$ & $75 \cdot 0$ & $45 / 60$ & 0.90 & $0.77,1.06$ & - & - \\
\hline \multicolumn{13}{|l|}{ Birth weight (g) } \\
\hline$\geq 3500$ & $62 \cdot 0$ & $31 / 50$ & $1 \cdot 00$ & Ref. & - & - & $75 \cdot 0^{\star}$ & $60 / 80$ & $1 \cdot 00$ & Ref. & $1 \cdot 00$ & Ref. \\
\hline$<3500$ & $62 \cdot 2$ & $51 / 82$ & $1 \cdot 00$ & $0 \cdot 76,1 \cdot 32$ & - & - & $86 \cdot 0^{\star}$ & $98 / 114$ & $1 \cdot 16$ & $0.99,1.35$ & $1 \cdot 15$ & $1 \cdot 00,1 \cdot 34$ \\
\hline
\end{tabular}

ID, iron deficiency; PR, prevalence ratio; Ref., reference category.

tTotals differ from the total number of study children due to missing values. 
during pregnancy, gestational anaemia, teenage pregnancies, shorter interval between births, early clamping of the umbilical cord) influencing the nutritional status of the child at birth (low weight, prematurity, low Fe reserves) ${ }^{(22,23)}$. A study conducted by Sharmanov ${ }^{(24)}$ in Central Asia reported that $68 \%$ of infants under 3 years born to anaemic mothers also exhibited anaemia. By contrast, the problem was identified in only $24 \%$ of infants born to non-anaemic mothers. Employing standardized methods, the large study examined clusters of three countries and involved 11750 mothers and their infants. Three other studies, from Spain, Jordan and Indonesia ${ }^{(25-27)}$, demonstrated a higher incidence of ID or IDA in infants born to mothers with IDA during pregnancy, as compared with infants born to mothers with adequate Fe status.

In the present study, the information collected for the two periods precludes an assessment of the evolution of gestational status and its relationship with ID in the children. However, the cross-sectional analysis of the 2007 survey data ${ }^{(11)}$ assessing factors linked to anaemia in children showed a $55 \%$ greater prevalence of anaemia in children under 2 years born to mothers who had more than three gestations.

In an effort to propose hypotheses explaining the high prevalence of ID and anaemia in the children studied, a nationwide study on the progress and changes in maternal and infant health was undertaken ${ }^{(9)}$ using data drawn from population censuses and national demography and health surveys. Findings showed, despite broader national coverage for delivery and prenatal periods, a prevailing low quality of prenatal care in various regions of the country, particularly in low-income regions such as the Brazilian Amazon. This care was characterized by a lack of, or poor, integration of key services, predisposing both mother and child to a series of nutritional deficits. Furthermore, overuse of surgical delivery has been observed in recent years ${ }^{(9)}$. Despite broader coverage for prenatal care, this finding was corroborated by the results of our study with a $52 \%$ rise in caesarean section. According to our data, caesarean sections accounted for $40 \%$ of births, far exceeding the WHO-recommended $15 \%$ limit $^{(28)}$. This abuse of caesarean sections is thought to have various repercussions which in turn impact Fe reserves in infants, such as an increase in preterm births ${ }^{(29)}$. A systematic review $^{(30)}$ of population-based studies assessing preterm births in Brazil showed a significant increase over the past 20 years. Prematurity is the leading cause of infant deaths in Brazil, predisposing infants to greater nutritional risk, particularly anaemia, due to low Fe status at birth. Despite higher prematurity rates, the prevalence of low birth weight has remained stable at $8 \%$ since $2000^{(9)}$, a level similar to that found in the present study. One explanation for this trend of stable low birth weight concomitant with higher prematurity may lie in the lower frequency of intra-uterine growth restriction ${ }^{(31)}$.
Another aspect to consider is whether the increase in surgical deliveries is linked to more routine early clamping of the umbilical cord in neonates (performed within 1 min of birth), a procedure common in Brazilian hospitals and a practice associated with increased risk of ID in children ${ }^{(32)}$. However, deliveries performed by midwives, formerly common practice in Acrelândia, have given way to hospital deliveries which include early clamping of the umbilical cord. According to our 2007 data, the prevalence of ID was significantly greater in surgically delivered neonates, with the condition affecting $90 \%$ of this infant group.

Besides these perinatal factors, underlying postnatal factors have been extensively discussed in studies investigating ID in early infancy. These factors include monotonous diets, with early introduction of cow's milk, and diets that are milk-based or that offer low Fe bioavailability ${ }^{(33,34)}$. This inadequate dietary pattern was previously described in the children from the present study area in 2003 and $2007^{(12,13)}$. A study by Castro et $a{ }^{(12)}$ assessing a sub-sample of the under- $2 \mathrm{~s}$ from the 2003 survey identified irregular consumption of meats, fruit and vegetables (promoters of Fe absorption) together with a high intake of cow's milk and thickeners (absorption inhibiters), resulting in a low intake of Fe of animal origin and low amounts of bioavailable $\mathrm{Fe}$ in the diet (median: $0.3 \mathrm{mg}$; interquartile range: $0 \cdot 2-0.3 \mathrm{mg}$ ). In 2007 , based on data reported by Garcia et $a l .{ }^{(13)}$, we concluded that this situation failed to improve, and was likely exacerbated, as a result of the low intake of vitamins A, C, folic acid and Zn. Other contributory factors were low bioavailability of $\mathrm{Fe}$ in the diet, calculated as $8 \%$, in conjunction with overconsumption of cow's milk, porridge and ultra-processed foods; the amount of bioavailable $\mathrm{Fe}$ in the diet remained similar to levels verified in 2003. It was also noted that, although national surveys ${ }^{(3)}$ indicated improvements in breastfeeding patterns, the region under study continued to show low rates of breast-feeding together with early introduction of cow's milk to replace breast milk, thereby raising the risk for ID in infants under 2 years of age.

Also in relation to dietary patterns, national surveys conducted in Brazil in 2002 and $2008^{(35,36)}$ collecting data on household food acquisition showed a deterioration in the pattern of consumption of the population of the state of Acre, reflecting the trend in other regions of the country. This shift can increase the risk of ID in the mother-infant population. Specifically in Acre State, a reduction in the consumption of foods rich in $\mathrm{Fe}$ and absorption promoters was found, with a $36 \%$ decrease in seafood, an $18 \%$ decrease in fruit and vegetables and a $22 \%$ drop in fortified flour consumption, whereas the intake of meat and poultry remained stable. In parallel, an increase in the acquisition of foods that inhibit $\mathrm{Fe}$ absorption was evident such as milk (32\% increase), processed foods (200\% increase) and processed meat 
products such as frankfurters and mortadella (150\% increase).

In addition to continued poor diet with possible decline in quality, a lack of improvement in both environmental sanitary conditions and morbidity patterns was observed, with persistent high rates of diarrhoea ( $40 \%$ ) and intestinal parasites (20\%), exceeding levels reported in poor regions of the world such as south central $\mathrm{Nepal}^{(37)}$ and in a rural South African community ${ }^{(38)}$. The influence of housing and sanitation in the development of anaemia and ID is expected in areas with substandard living conditions, predisposing to infections and parasitic diseases which deplete the children, further contributing to nutritional deficiencies ${ }^{(4)}$.

Although the scope of the present study did not include an assessment of the strategies adopted by the Brazilian government for combating anaemia and ID in Amazonian children, the data obtained allow us to discuss these actions in light of the lack of studies reporting on the effectiveness of these strategies in Brazil. The first point to be raised is that the PNSF has yet to gain adherence of mothers and children, evidenced by the low prevalence of use of vitamin and mineral supplements of about $15 \%$ for the period covered by the surveys. In addition to early discontinuation of supplement use, other factors related to low adherence and considered barriers to the success of Fe supplementation include sensory aspects, collateral effects and lack of information ${ }^{(39,40)}$. Some studies conducted in Brazil suggest reappraisal of the Fe dosages used by the $\mathrm{PNSF}^{(41)}$.

With regard to compulsory fortification of wheat and corn flours, according to estimates by Bell and Oakley ${ }^{(42)}$, $27 \%$ of the world population has access to flour fortified with Fe and/or folic acid. Fortification of flour with Fe and folic acid has produced positive results in the USA, Canada and Chile, reducing the frequency of neural tube defects in newborns. However, results of fortification of flour with Fe for the prevention of anaemia in infancy suggest a low level of effectiveness. In Brazil, considering its large geographical extent and the different infant feeding practices across the country, there is a need for further studies in assessing the nationwide effectiveness of the flour fortification programme. A study carried out in the south of Brazil with series of population-based surveys (in 2004, 2005, 2006 and 2008) to ascertain the effect of flour fortification in pre-school children after a 4-year programme revealed no impact of flour fortification, with an increase in anaemia prevalence among children under 24 months of age ${ }^{(43)}$. Numerous hypotheses have been proposed to justify the ineffectiveness of large-scale fortification in developing countries, one of which holds that flour is an unsuitable dietary vehicle for targeting infants given this group's low flour intake; while other proposed barriers include a lack of monitoring and standardizing of the fortification process plus the use of Fe compounds with low bioavailability ${ }^{(43,44)}$. The use of less readily absorbed compounds and their associated cost are real issues facing developing countries; since flours tend to be stored for long periods, the use of other more easily absorbed compounds such as ferrous sulfate can produce sensory alterations ${ }^{(45)}$.

Recent recommendations by the WHO for the prevention of ID and anaemia in infants and children include the use of multiple-micronutrient powders for home fortification of foods. This home fortification should be integrated with basic health-care actions, given that insufficient $\mathrm{Fe}$ intake tends to be accompanied by threshold or insufficient consumption of other micronutrients required to metabolize $\mathrm{Fe}$ and needed for normal growth and development ${ }^{(46)}$. A systematic review ${ }^{\left({ }^{(4)}\right)}$ on the impact of home fortification suggested that besides being more effective it is better accepted owing to fewer side-effects and, when used in conjunction with nutritional guidance actions, can result in improvements in overall dietary quality.

In light of the environmental health and nutrition scenario of the children studied, particularly the alarming prevalence of ID, and based on successful experiences in other countries in controlling this deficiency, a reformulation of the current strategies adopted in developing countries such as Brazil is warranted. These measures should extend to include more impoverished regions and actions to improve basic sanitation, drinking water supplies, access to quality maternal and infant health care, and to guidance on healthy complementary foods, without which novel strategies may also fail to have positive outcomes.

\section{Acknowledgements}

Sources of funding: The study was funded by the Conselho Nacional de Desenvolvimento Científico e Tecnológico (CNPq) and the Fundação de Amparo à Pesquisa do Estado de São Paulo (FAPESP; grant no. 2009/02640-1). F.S.G. received a Master scholarship from the FAPESP (grant no. 2009/02640-1) Conflict of interest declaration: There is no conflict of interest. Authorship responsibilities: F.S.G. and M.A.C. were responsible for the study design, project management, data analysis, interpretation of the results and manuscript writing. R.A.A. was responsible for data analysis, interpretation of results and manuscript writing. P.T.M. was responsible for the study design and project management. Acknowledgements: The authors express sincere appreciation to CNPq and FAPESP for funding. They would like to thank the research teams of 2003 and 2007; the community health workers and the mothers and children who participated in the study; and Tegan Condon for critical reading of the manuscript.

ACTION (ACre nutriTION) Study Working Group: Pascoal Torres Muniz, Orivaldo Florencio Souza, Cristieli Sergio de Menezes Oliveira, Thiago Santos de Araujo 
(Department of Health Sciences, Federal University of Acre, Rio Branco, Brazil); Suely de Godoy Agostinho Gimeno, Luciana Yuki Tomita (Department of Preventive Medicine, Federal University of São Paulo, São Paulo, Brazil); Marcelo Urbano Ferreira (Institute of Biomedical Sciences, University of São Paulo, São Paulo, Brazil); Kézia K.G. Scopel (Department of Parasitology, Immunology and Microbiology, Federal University of Juiz de Fora, Juiz de Fora, Brazil); Barbara Hatzlhoffer Lourenço, Pablo Secato Fontoura, Fernanda Serra Granado, Fernanda Cobayashi, Rosangela Aparecida Augusto, Marly Augusto Cardoso (Department of Nutrition, School of Public Health, University of São Paulo, São Paulo, Brazil).

\section{References}

1. World Health Organization (2001) Iron Deficiency Anaemia: Assessment, Prevention and Control. A Guide for Programme Managers. WHO/NHD/O.13. Geneva: WHO.

2. World Health Organization (2004) Assessing the Iron Status of Populations. Geneva: WHO.

3. Ministério da Saúde (2008) PNDS 2006 - National Demographic and Health of Children and Women. Brasília: Ministry of Health.

4. World Health Organization (2008) Worldwide Prevalence of Anaemia 1993-2005. WHO Global Database on Anaemia. Geneva: WHO.

5. International Nutrition Foundation \& Micronutrient Initiative (1998) Preventing Iron Deficiency in Women and Children: Technical Consensus on Key Issues and Resources for Programme Advocacy, Planning and Implementation. UNICEF/WHO/UNU/MI Technical Workshop, UNICEF, New York, 7-9 October 1998. Boston, MA and Ottawa, ON: INF and MI.

6. World Health Organization (2001) Expert Consultation on the Optimal Duration of Exclusive Breastfeeding. Conclusions and Recommendations. WHO/A54/INF/DOC./4. Geneva: WHO.

7. Ministério da Saúde (2005) Operating Manual: National Program for Iron Supplementation. Brasília: Ministry of Health.

8. Ministério da Saúde (2002) Technical Regulations for Fortification of Wheat Flour and Corn Flour With Iron and Folic Acid. RDC 344. http://www.anvisa.gov.br/legis/ resol/2002/344_02rdc.htm (accessed April 2012).

9. Victora CG, Aquino EM, do Carmo Leal M et al. (2011) Maternal and child health in Brazil: progress and challenges. Lancet 377, 1863-1876.

10. Muniz PT, Castro TG, Araujo TS et al. (2007) Child health and nutrition in the Western Brazilian Amazon: populationbased surveys in two counties in Acre State. Cad Saude Publica 23, 1283-1293.

11. Cardoso MA, Scopel KKG, Muniz PT et al. (2012) Underlying factors associated with anemia in Amazonian children: a population-based, cross-sectional study. PLoS One 7, e36341.

12. Castro TG, Baraldi LG, Muniz PT et al. (2009) Dietary practices and nutritional status of 0-24-month-old children from Brazilian Amazonia. Public Health Nutr 12, $2335-2342$.

13. Garcia MT, Granado FS \& Cardoso MA (2010) Complementary feeding and nutritional status of 6-24 month-old children in Acrelândia, Acre State, Western Brazilian Amazon. Cad Saude Publica 27, 305-316.

14. Lohman TG, Roche AF \& Martorell R (1998) Anthropometric Standardization Reference Manual. Champaign, IL: Human Kinetics Books.
15. World Health Organization (2006) WHO child growth standards based on length/height, weight and age. Acta Paediatric Suppl 450, 76-85.

16. Thomas-Hudson M, Bingham KC \& Simmons WK (1994) An evaluation of the Hemocue for measuring haemoglobin in field studies in Jamaica. Bull World Health Organ 73, 423-426.

17. DeMaeyer EM, Dallman P, Gurney JM et al. (1989) Preventing and Controlling Iron Deficiency Anaemia Through Primary Health Care. Geneva: WHO.

18. Cook JD, Skikne BS \& Baynes RD (1993) Serum transferring receptor. Annu Rev Med 44, 63-74.

19. Hoffman W, Pons JA \& Janer JL (1934) The sedimentation concentration method in Schistosomiasis mansoni. PR J Public Health Trop Med 9, 283-291.

20. Instituto Brasileiro de Geografia e Estatística (2000) Resultados da amostra do censo demográfico 2000. http:// www.ibge.gov.br/home/estatística/populacao/censo2000/ populacao/pop_Censo2000.pdf (accessed May 2006).

21. World Health Organization (1995) Physical Status: Uses and Interpretation of Anthropometry. Report of a WHO Expert Committee. WHO Technical Report Series no. 854. Geneva: WHO.

22. Chaparro CM (2008) Setting the stage for child health and development: prevention of iron deficiency in early infancy. J Nutr 138, 2529-2533.

23. Balarajan Y, Ramakrishnan U, Ozaltin E et al. (2011) Anaemia in low-income and middle-income countries. Lancet 378, 2123-2135.

24. Sharmanov A (1998) Anaemia in Central Asia: demographic and health survey experience. Food Nutr Bull 19, 307-317.

25. Colomer J, Colomer C, Gutierrez D et al. (1990) Anaemia during pregnancy as a risk factor for infant iron deficiency: report from the Valencia Infant Anaemia Cohort (VIAC) study. Paediatr Perinat Epidemiol 4, 196-204.

26. Kilbride J, Baker TG, Parapia LA et al. (1999) Anaemia during pregnancy as a risk factor for iron deficiency anaemia in infancy: a case-control study in Jordan. Int J Epidemiol 28, 461-468.

27. de Pee S, Bloem MW, Sari M et al. (2002) The high prevalence of low hemoglobin concentration among Indonesian infants aged $3-5$ months is related to maternal anemia. J Nutr 132, 2215-2221.

28. World Health Organization (1985) Appropriate technology for birth. Lancet 2, 436-437.

29. Silva AA, Barbieri MA, Bettiol H et al. (2004) Can we explain why Brazilian babies are becoming lighter? Int J Epidemiol 33, 821-828.

30. Silveira MF, Santos IS, Barros AJ et al. (2008) Increase in preterm births in Brazil: review of population-based studies. Rev Saude Publica 42, 957-964.

31. Barros FC, Victora CG, Matijasevich A et al. (2008) Preterm births, low birth weight, and intrauterine growth restriction in three birth cohorts in Southern Brazil: 1982, 1993 and 2004. Cad Saude Publica 24, Suppl. 3, S390-S398.

32. Hutton EK \& Hassan ES (2007) Late vs. early clamping of the umbilical cord in full-term neonates: systematic review and meta-analysis of controlled trials. JAMA 297, $1241-1252$.

33. Oliveira MAA, Osório MM \& Raposo MCF (2007) Socioeconomic and dietary risk factors for anemia in children aged 6 to 59 months. J Pediatr 83, 39-46.

34. Hadler MC, Colugnati FA \& Sigulem DM (2004) Risks of anemia in infants according to dietary iron density and weight gain rate. Prev Med 39, 713-721.

35. Instituto Brasileiro de Geografia e Estatística (2004) Household Budget Survey 2008-2009: Per Capita Household Food Acquisition. http://www.ibge.gov.br/home/estatistica/ populacao/condicaodevida/pof/2002analise/default.shtm (accessed July 2011). 
36. Instituto Brasileiro de Geografia e Estatística (2010) Household Budget Survey 2008-2009: Per Capita Household Food Acquisition. http://www.ibge.gov.br/home/estatistica/ populacao/condicaodevida/pof/2008_2009_aval_nutricional/ default.shtm (accessed July 2011).

37. Siegel EH, Stolzfus RJ, Khatry SK et al. (2006) Epidemiology of anaemia among 4- to-17-month-old children living in south central Nepal. Eur J Clin Nutr 60, 228-235.

38. Faber M \& Benadé AJS (1999) Nutritional status and dietary practices of 4-24-month-old children from a rural South Africa community. Public Health Nutr 2, 179-185.

39. Mora J (2002) Iron supplementation: overcoming technical and practical barriers. J Nutr 132, Suppl. 4, 853S-855S.

40. Shibukawa AF, Silva EM, Ichiki WA et al. (2008) Prophylaxis for iron deficiency anaemia using ferrous sulfate among infants followed up at a primary healthcare unit in the municipality of Embu-SP (2003/2004). Sao Paulo Med J 126, 96-101.

41. Azeredo CM, Cotta RM, Sant'Ana LF et al. (2010) Greater effectiveness of daily iron supplementation scheme in infants. Rev Saude Publica 44, 230-239.
42. Bell KN \& Oakley GP (2009) Update on prevention of folic acid-preventable spina bifida and anencephaly. Birth Defects Res A Clin Mol Teratol 85, 102-107.

43. Assunção MC, Santos IS, Barros AJ et al. (2012) Flour fortification with iron has no impact on anaemia in urban Brazilian children. Public Health Nutr 15, 1796-1801.

44. Zimmermann MB \& Hurrell RF (2007) Nutritional iron deficiency. Lancet 370, 511-520.

45. Hurrell R, Bothwell T, Cook JD et al. (2002) The usefulness of elemental iron for cereal flour fortification: a SUSTAIN Task Force report. Sharing United States Technology to Aid in the Improvement of Nutrition. Nutr Rev 60, 391-406.

46. World Health Organization (2011) Use of Multiple Micronutrient Powders for Home Fortification of Foods Consumed by Infants and Children 6-23 Months of Age. Geneva: WHO.

47. Dewey KG, Yang Z \& Boy E (2009) Systematic review and meta-analysis of home fortification of complementary foods. Matern Child Nutr 5, 283-321. 